\title{
Association of Cystatin C with Metabolic Syndrome and Its Prognostic Performance in Non-ST-Segment Elevation Acute Coronary Syndrome with Preserved Renal Function
}

\author{
Qi Mao $(D),{ }^{1}$ Ning Zhao, ${ }^{1}$ Yuqing Wang, ${ }^{1}$ Youmei Li, ${ }^{1}$ Chaojun Xiang, \\ Lufeng $\mathrm{Li}^{1}{ }^{1}$ Wei Zheng $\mathbb{D}^{1},{ }^{1}$ Shangcheng $\mathrm{Xu}^{2}$, and Xiao-Hui Zhao $\mathbb{D D}^{1}$ \\ ${ }^{1}$ Department of Cardiovascular Medicine, Institute of Cardiovascular Research, Xinqiao Hospital, \\ Army Medical University, Chongqing 400037, China \\ ${ }^{2}$ Department of Occupational Health, Army Medical University, Chongqing 400038, China
}

Correspondence should be addressed to Xiao-Hui Zhao; doctorzhaoxiaohui@yahoo.com

Received 9 December 2018; Accepted 11 April 2019; Published 16 June 2019

Academic Editor: Luenda Charles

Copyright (C) 2019 Qi Mao et al. This is an open access article distributed under the Creative Commons Attribution License, which permits unrestricted use, distribution, and reproduction in any medium, provided the original work is properly cited.

\begin{abstract}
Objective. The underlying mechanisms by which cystatin $\mathrm{C}$ affects cardiovascular disease (CVD) are not very clear. Metabolic syndrome (MetS) is a cluster of risk factors that increase the risk of CVD. Here, we aimed to investigate the association of cystatin C with metabolic syndrome and cardiovascular outcomes in non-ST-segment elevation acute coronary syndrome (NSTE-ACS) with preserved renal function. Methods. In total, 422 NSTE-ACS patients with preserved renal function were enrolled to examine the association of cystatin C with MetS. MetS was defined based on the NCEP-ATP-III guidelines. Major adverse cardiovascular events (MACEs) were also evaluated, which included cardiac death, nonfatal myocardial infarction (MI), target vessel revascularization (TVR), heart failure, and nonfatal stroke. All patients underwent a 12-month follow-up for MACEs after admission. Results. Cystatin $\mathrm{C}$ was significantly correlated with metabolic risk factors and inflammation markers. The prevalence of MetS and MACEs correlated with cystatin C levels. Cystatin C showed a strong diagnostic performance for cardiovascular risk factors and outcomes in ROC analysis. After adjustment for multiple risk factors, cystatin C level was independently associated with MetS (OR 2.299, 95\% CI 1.251-4.225, and $\mathrm{P}=0.007)$. During a 12-month follow-up, the patients with high cystatin $\mathrm{C}$ level and MetS had higher incidence of MACEs (Log-rank $=24.586, \mathrm{P}<0.001)$ and cardiac death (Log-rank $=9.890, \mathrm{P}=0.020$ ) compared to the others. Multivariate Cox analysis indicated that cystatin C level was an independent predictor of MACEs (HR 2.609, 95\% CI 1.295-5.257, and P = 0.007). Conclusion. Cystatin $\mathrm{C}$ may be an independent predictor of metabolic syndrome and therefore valuable for management of NSTE-ACS patients. Further multicenter, large-scale studies are required to assess the implication of these results.
\end{abstract}

\section{Introduction}

Cystatin $\mathrm{C}$ is an endogenous inhibitor of cathepsin cysteine proteases and is generally considered to be constantly secreted and be freely filtered by the glomerulus but be neither secreted by the renal tubule nor reabsorbed into circulation $[1,2]$. Therefore, cystatin $\mathrm{C}$ is useful for estimation of glomerular filtration rate (GFR) and known as a marker of renal function $[3,4]$.

Recent studies have described cystatin $\mathrm{C}$ as a prominent predictor of cardiovascular diseases (CVD) that is significantly associated with high risk of cardiovascular outcomes in acute coronary syndrome (ACS) $[5,6]$. Until now, the reasons by which cystatin $\mathrm{C}$ is associated with cardiovascular outcomes were mostly attributed to its higher sensitivity for identifying early renal impairment [7-9]. However, increasing evidence indicated that cystatin $\mathrm{C}$ not only was a marker of GFR but also was correlated with inflammation and oxidative stress in CVD [10-12]. The Prospective Epidemiological Study of Myocardial Infarction (PRIME) showed that cystatin $\mathrm{C}$ was associated with coronary events independent of estimated GFR [13]. Tangri et al. [14] also reported that cystatin $\mathrm{C}$ remained associated with cardiovascular events even after adjustment for directly measured GFR. These 
results indicated that cystatin $\mathrm{C}$ was a predictor of cardiovascular events independent of renal function and implied that non-GFR determinants of cystatin $\mathrm{C}$ might be related to cardiovascular outcomes.

Of note, several studies have reported that hypertension, dyslipidemia, and diabetes were associated with cystatin $\mathrm{C}$ level, which were the components of metabolic syndrome (MetS) and cardiometabolic risk factors [15-17]. Interestingly, recent cross-sectional studies also showed that cystatin $\mathrm{C}$ level increased in patients with MetS and may be used as a marker of MetS in general population [18-20]. MetS, characterized by glucose and lipid disorder, is an important risk factor for ACS and is an increasing epidemic worldwide [2123]. To the best of our knowledge, the relationship between cystatin $\mathrm{C}$ and metabolic risk factors remains unclear in ACS, and no studies have explored the association of cystatin $\mathrm{C}$ with MetS in NST-ACS. We hypothesized that cystatin C might be associated with MetS independent of renal function and therefore aimed to investigate the role of non-GFR determinants of cystatin $\mathrm{C}$ on cardiovascular risk factors and major adverse cardiovascular events (MACEs) in NSTE-ACS.

\section{Materials and Methods}

2.1. Study Population. The study protocol complied with the Declaration of Helsinki and was approved by Xinqiao Hospital Ethics Committee, Army Military Medical University (Chongqing, China). All patients provided informed consent.

This was a prospective observational study consisting of 797 consecutive patients with NSTE-ACS patients with preserved renal function who were admitted between January 2017 and September 2017. The inclusion criteria were as follows: (1) with complete clinical information; (2) all patients underwent coronary angiography; and (3) preserved renal function defined as estimated glomerular filtration rate $(\mathrm{eGFR}) \geq 60 \mathrm{~mL} / \mathrm{min} * 1.73 \mathrm{~m}^{2}$ at admission. The exclusion criteria were nonobstructive coronary disease, primary cardiomyopathy and valvular heart disease, primary kidney disease, severe hepatic dysfunction, significant infection, thyroid and adrenal cortex dysfunction, autoimmune diseases, use of steroids and immune inhibitors, hematologic disorders, surgery or trauma 3 month prior to participation, and malignant diseases. Finally, a cohort of 422 patients was enrolled in this study.

2.2. Data Collection and Follow-up. Clinical data were collected from medical records by trained physicians. These included demographic data, medical history, laboratory parameters, and basic medication information. The venous blood samples were collected after overnight fasting before coronary angiography, and routine biochemical indicators were measured by automatic biochemical analyzer (DXC800, Beckman Coulter, USA). Concentration of serum cystatin $\mathrm{C}$ was determined by particle-enhanced turbidimetric immunoassay (PETIA) method. The angiographic data were obtained from the cardiac catheterization laboratory records. The synergy between percutaneous coronary intervention with TAXUS and cardiac surgery (SYNTAX) scores for quantifying coronary lesions was assessed by experienced interventional cardiologists using the score calculator (version 2.28) in SYNTAX score website. Primary outcomes were major adverse cardiovascular events (MACEs) defined as the combination of cardiac death, nonfatal myocardial infarction, target vessel revascularization (TVR), heart failure, and nonfatal stroke [24]. All patients had 12-month follow-up after admission, and follow-up data were obtained from hospital records (39 cases, 9.2\%) or by interviewing (in person or by telephone) patients (369 cases, $87.5 \%$ ) and their families (14 cases, $3.3 \%$ ).

2.3. Definition. The definition of NSTE-ACS complied with the current guidelines of the European Society of Cardiology (ESC) [25]. Global Registry of Acute Coronary Events (GRACE) risk score was applied to stratification and prediction of risk in patients with ACS and was calculated based on the clinical history, electrocardiogram, and laboratory parameters at admission [26]. Multivessel disease was a type of complex coronary artery disease associated with poor prognosis, defined as at least double-vessel disease or left main disease with $>50 \%$ luminal narrowing [27]. SYNTAX score was a clinical tool for quantifying coronary lesions and was dependent of all coronary lesions with > 50\% diameter stenosis in a vessel $>1.5 \mathrm{~mm}$ [28]. The basic drug treatment for the NSTE-ACS patients was in compliance with the current ESC guidelines [25]. Percutaneous coronary intervention (PCI) was a conventional treatment strategy for revascularization and reperfusion in patients with ACS and was determined by experienced cardiologists based on individual risk and decisions from patients. Metabolic syndrome (MetS) was a cluster of metabolic disorders associated with CVD and its definition complied with National Cholesterol Education Program's Adult Treatment Panel III (NCEP ATP III) criteria [29]. Estimated glomerular filtration rate (eGFR) reflected renal impairment and was calculated based on the Modification of Diet in Renal Disease (MDRD) Study equation: eGFR $\left(\mathrm{mL} / \mathrm{min} * 1.73 \mathrm{~m}^{2}\right)=186 \times \mathrm{Scr}^{-1.154} \times$ age $^{-0.203} \times 1.233 \times 0.742$ (if female) [30]. C-reactive protein (CRP) and B-type natriuretic peptide (BNP) were markers of inflammation and heart failure, respectively. Both of them were, respectively, converted into binary categorical variables by $5 \mu \mathrm{g} / \mathrm{mL}$ as the cutoff value of elevated CRP level and 100 $\mathrm{pg} / \mathrm{mL}$ as the cutoff value of elevated BNP level [31, 32]. Killip class was used for clinical grading of heart failure caused by acute myocardial infarction. Killip class $>1$ was considered as elevated Killip class. SYNTAX $\geq 23$ and GRACE $\geq 89$ were, respectively, defined as a high SYNTAX score and a high GRACE score $[26,28]$.

2.4. Statistical Analysis. Continuous variables were expressed as mean $\pm \mathrm{SD}$ or median (IQR) according to the presence or absence of normal distribution, and categorical data were expressed as frequencies and percentages. To compare the baseline characteristics, the study population was divided into two groups by the median cystatin C level $(0.90 \mathrm{mg} / \mathrm{L})$ of the cohort: low cystatin $C$ group $(\leq 0.90 \mathrm{mg} / \mathrm{L})$ and high cystatin $\mathrm{C}$ group $(>0.90 \mathrm{mg} / \mathrm{L})$. The $t$ test was used if continuous variables were normally distributed, while the Mann-Whitney $U$ test was applied if continuous variables 
were not normally distributed. Differences in categorical variables were evaluated by the Chi-squared test or Fisher exact test. Correlation was assessed using the Spearman rank correlation test. Diagnostic performances of cystatin C on cardiovascular risk factors and outcomes were assessed by the receiver operating characteristic (ROC) curve analysis. Logistic regression was applied to explore the association between cystatin $\mathrm{C}$ and MetS, and the variables with unadjusted $\mathrm{P}$ value of $<0.1$ were selected as potential risk factors and included in the multivariate model. Event-free survival time was defined as from the date of admission to the date of cardiovascular events as verified during the follow-up. Survival curves or cumulative risk curves for cardiovascular outcomes were constructed using the KaplanMeier method, with differences assessed using the log-rank test. Cox regression analyses were performed to evaluate the association of cystatin C with MACEs. Multivariate Cox models were adjusted for established cardiovascular risk factors (age, gender, smoking, hypertension, diabetes, LDL$\mathrm{C}$, and HDL-C), clinical variables affecting cardiovascular outcomes (Killip class, GRACE scores, and SYNTAX scores), medication (ACEI/ARB, $\beta$-blocker, and PCI/CABG), and variables that might affect cystatin $C$ levels (BMI, eGFR, and $\mathrm{CRP}$ ). Adjusted model 1 included age, gender, BMI, smoking, hypertension, diabetes, LDL-C, and HDL-C; and adjusted model 2 same as model 1 plus eGFR, CRP, Killip class $>1$, GRACE scores, SYNTAX scores, ACEI/ARB, $\beta$-blocker, and $\mathrm{PCI} / \mathrm{CABG}$. $\mathrm{P}<0.05$ was considered statistically significant. All statistical analyses were performed using SPSS software version 22.0 (SPSS, Inc., Chicago, Illinois).

\section{Results}

3.1. Baseline Characteristics of the Study Population. The characteristics of the study population are described in Table 1. Patients in the high cystatin $\mathrm{C}$ group were older than those in the low cystatin $\mathrm{C}$ group $(\mathrm{P}<0.001)$. The patients in the high cystatin $\mathrm{C}$ group had a higher incidence of diabetes $(\mathrm{P}=$ $0.036)$ and Met $\mathrm{P}(\mathrm{P}=0.001)$, had more severe coronary artery lesion $(\mathrm{P}<0.001)$, and had a higher GRACE score $(\mathrm{P}<0.001)$. Significant differences in clinical laboratory parameters were also observed in the two groups.

3.2. Correlation of Cystatin C, Creatinine, and eGFR-MDRD with Other Clinical Variables. Spearman rank correlation analysis was used to examine the correlation of cystatin $\mathrm{C}$, creatinine and eGFR-MDRD with other clinical variables. Compared to creatinine and eGFR-MDRD, cystatin C showed greater correlation with metabolic parameters, inflammation markers, and other cardiovascular risk factors (Table 2).

\subsection{Comparison of Cardiovascular Risk Factors and Events} according to Restratification Based on Cystatin C Level and Metabolic Syndrome. Furthermore, we stratified the subjects with or without MetS into the following four groups based on cystatin C levels: low cystatin C/MetS $(-)(\mathrm{n}=160)$, low cystatin C/MetS $(+)(\mathrm{n}=51)$, high cystatin C/MetS $(-)(\mathrm{n}$ $=128)$, and high cystatin C/MetS $(+)(\mathrm{n}=83)$. Elevated
CRP level, elevated BNP level, elevated Killip class, high GRACE score, multivessel disease, high SYNTAX score, and MACEs were significantly different among the four groups $(\mathrm{P}<0.001)$, and the high cystatin $\mathrm{C} / \mathrm{Met} S(+)$ group had more cardiovascular risk factors and events than the other three groups (Table 3). In addition, comparisons of baseline cystatin C levels in the NSTE-ACS patients with or without Killip class $>1$, multivessel disease, high SYNTAX score, high GRACE score, MetS, and MACEs are shown in Figure 1.

\subsection{Diagnostic Performance of Cystatin C for Cardiovascular} Risk Factors and Outcomes. In ROC curve analysis, the predictive cutoff values of cystatin $\mathrm{C}$ were constructed according to the ROC curves for identifying the patients with more cardiovascular risk factors, and for predicting the occurrence of MACEs. According to the area under the curve (AUC), cystatin $\mathrm{C}$ showed a powerful diagnostic performance for cardiovascular risk factors and outcomes. Using the cutoff points, the predictive values of cystatin $\mathrm{C}$ for MetS and MACEs were $1.01 \mathrm{mg} / \mathrm{L}$ and $0.87 \mathrm{mg} / \mathrm{L}$, respectively (Table 4).

3.5. Association of Cystatin C with Metabolic Syndrome. Potential risk factors for metabolic syndrome were chosen in univariate logistic regression analysis $(\mathrm{P}<0.1)$ and were used as the variables of multivariate model. The results indicated that cystatin $\mathrm{C}$ level was independently associated with metabolic syndrome (OR 2.299, 95\% CI 1.251-4.225, and $\mathrm{P}=0.007)$ (Table 5).

3.6. Association of Cystatin C with Cardiovascular Outcomes. Cox proportional hazard model was used to examine the association between cystatin $\mathrm{C}$ and cardiovascular outcomes during the 12-month follow-up. Univariate analysis showed that cystatin $\mathrm{C}$ was significantly associated with MACEs and its components. Confounders were included in the multivariate model for adjustment, and cystatin $\mathrm{C}$ remained to be an independent predictor of MACEs in adjusted models 1 (HR 2.677, 95\% CI 1.566-4.576, and P < 0.001) and 2 (HR $2.609,95 \%$ CI 1.295-5.257, and $P=0.007$ ) (Table 6). In the Kaplan-Meier analysis, the incidence of MACEs (Log-rank $=18.864, \mathrm{P}<0.001)$, cardiac death (Log-rank $=7.286, \mathrm{P}=$ 0.007), TVR (Log-rank $=5.103, P=0.024)$, and heart failure (Log-rank $=5.167, \mathrm{P}=0.023$ ) was higher in the high cystatin $\mathrm{C}$ group than that in the low cystatin $\mathrm{C}$ group. Moreover, the high cystatin C/MetS (+) group had the higher incidence of MACEs (Log-rank $=24.586, \mathrm{P}<0.001$ ) and cardiac death (Log-rank $=9.890, \mathrm{P}=0.020)$ than the other three groups (Figure 2).

\section{Discussion}

Our study focused on the link between non-GFR determinants of cystatin $\mathrm{C}$ and cardiometabolic risk factors and highlighted the predictive role of non-GFR determinants in NSTE-ACS. To the best of our knowledge, we for the first time examined the relationship between cystatin $\mathrm{C}$ and MetS in NSTE-ACS with preserved renal function. In our study, the main findings were as follows: (1) cystatin C was a powerful diagnostic indicator for cardiovascular risk factors; 


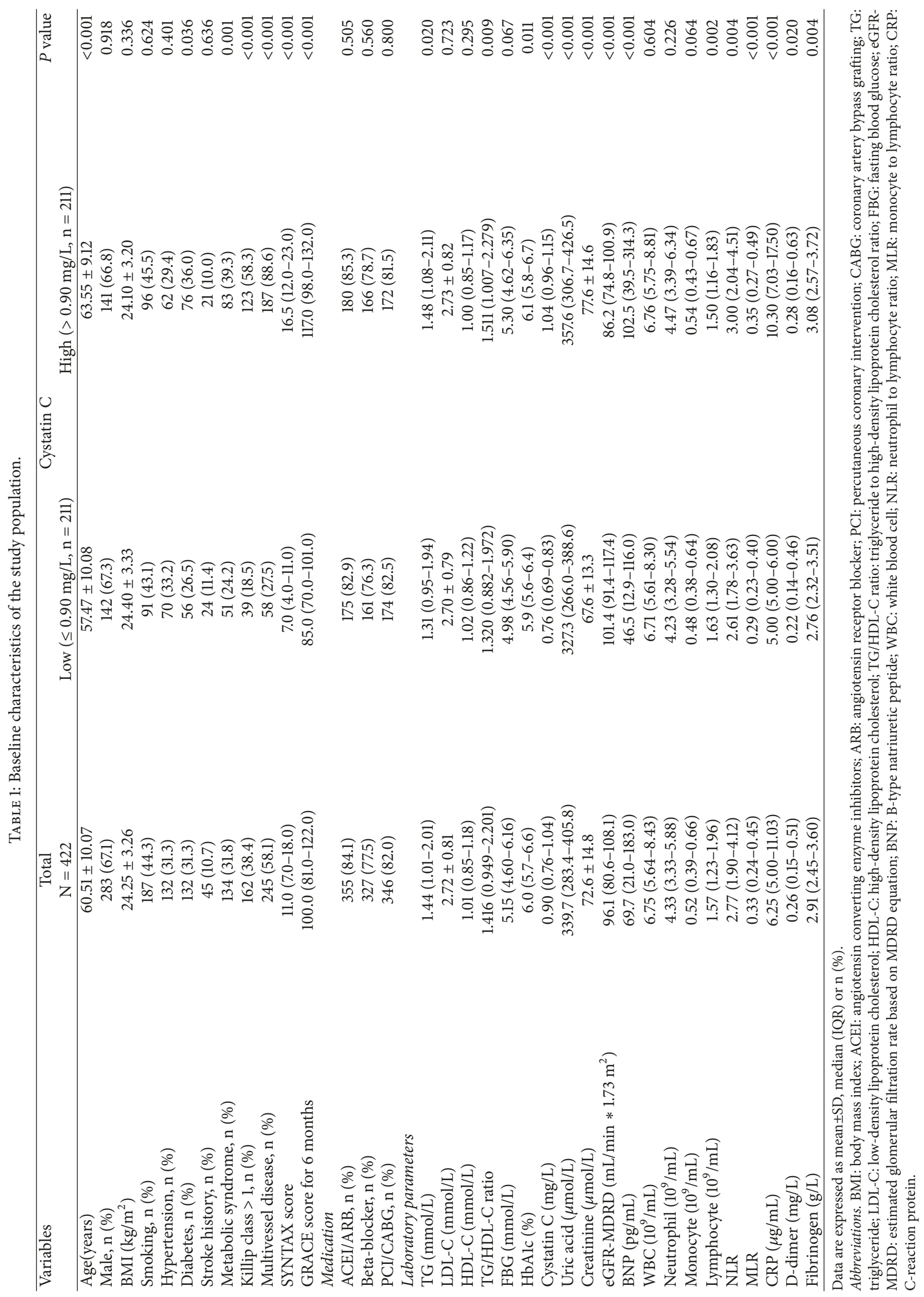


TABLE 2: Correlation of cystatin C, creatinine, and eGFR-MDRD with Other Clinical Variables.

\begin{tabular}{|c|c|c|c|c|c|c|}
\hline \multirow[b]{2}{*}{ Variables } & \multicolumn{2}{|c|}{ Cystatin C } & \multicolumn{2}{|c|}{ Creatinine } & \multicolumn{2}{|c|}{ eGFR-MDRD } \\
\hline & $r$ & $P$ value & $r$ & $P$ value & $r$ & $P$ value \\
\hline Age & 0.383 & $<0.001$ & 0.022 & 0.651 & -0.352 & $<0.001$ \\
\hline TG/HDL-C ratio & 0.133 & 0.006 & 0.110 & 0.024 & -0.035 & 0.473 \\
\hline TG & 0.109 & 0.025 & 0.055 & 0.261 & -0.061 & 0.209 \\
\hline FBG & 0.107 & 0.028 & 0.001 & 0.990 & -0.023 & 0.631 \\
\hline HbAlc & 0.128 & 0.008 & 0.016 & 0.740 & -0.087 & 0.074 \\
\hline Uric acid & 0.237 & $<0.001$ & 0.455 & $<0.001$ & -0.309 & $<0.001$ \\
\hline Creatinine & 0.394 & $<0.001$ & - & - & - & - \\
\hline eGFR-MDRD & -0.469 & $<0.001$ & -0.752 & $<0.001$ & - & - \\
\hline $\mathrm{BNP}$ & 0.328 & $<0.001$ & 0.125 & 0.010 & -0.199 & $<0.001$ \\
\hline GRACE score & 0.593 & $<0.001$ & 0.207 & $<0.001$ & -0.390 & $<0.001$ \\
\hline SYNTAX score & 0.597 & $<0.001$ & 0.247 & $<0.001$ & -0.319 & $<0.001$ \\
\hline Monocyte & 0.101 & 0.038 & 0.140 & 0.004 & -0.034 & 0.490 \\
\hline Lymphocyte & -0.165 & 0.001 & -0.057 & 0.240 & 0.045 & 0.352 \\
\hline NLR & 0.156 & 0.001 & 0.079 & 0.106 & -0.040 & 0.416 \\
\hline MLR & 0.217 & $<0.001$ & 0.188 & $<0.001$ & -0.065 & 0.182 \\
\hline CRP & 0.641 & $<0.001$ & 0.279 & $<0.001$ & -0.334 & $<0.001$ \\
\hline D-dimer & 0.166 & 0.001 & 0.034 & 0.486 & -0.178 & $<0.001$ \\
\hline Fibrinogen & 0.181 & $<0.001$ & 0.069 & 0.157 & -0.039 & 0.420 \\
\hline
\end{tabular}

Abbreviations. TG: triglyceride; HDL-C: high-density lipoprotein cholesterol; TG/HDL ratio: triglyceride to high-density lipoprotein cholesterol ratio; FBG: fasting blood glucose; eGFR-MDRD: estimated glomerular filtration rate based on MDRD equation; BNP: B-type natriuretic peptide; NLR: neutrophil to lymphocyte ratio; MLR: monocyte to lymphocyte ratio; CRP: C-reactive protein.

TABLE 3: Cardiovascular risk factors and follow-up cardiac events.

\begin{tabular}{|c|c|c|c|c|c|}
\hline & \multicolumn{2}{|c|}{ Low cystatin $\mathrm{C}(\leq 0.90 \mathrm{mg} / \mathrm{L}, \mathrm{n}=211)$} & \multicolumn{2}{|c|}{ High cystatin $\mathrm{C}(>0.90 \mathrm{mg} / \mathrm{L}, \mathrm{n}=211)$} & \multirow[b]{2}{*}{$P$ value } \\
\hline & $\operatorname{MetS}(-), \mathrm{n}=160$ & $\operatorname{MetS}(+), \mathrm{n}=51$ & MetS $(-), \mathrm{n}=128$ & $\operatorname{MetS}(+), \mathrm{n}=83$ & \\
\hline $\mathrm{CRP}>5 \mu \mathrm{g} / \mathrm{mL}, \mathrm{n}(\%)$ & $55(34.4)$ & $28(54.9)$ & $103(80.5)$ & $76(91.6)$ & $<0.001$ \\
\hline $\mathrm{BNP}>100 \mathrm{pg} / \mathrm{mL}, \mathrm{n}(\%)$ & $44(27.5)$ & $17(33.3)$ & $64(50.0)$ & $43(51.8)$ & $<0.001$ \\
\hline Killip class > 1, n (\%) & $30(18.8)$ & $9(17.6)$ & $74(57.8)$ & $49(59.0)$ & $<0.001$ \\
\hline Multivessel disease, $\mathrm{n}(\%)$ & $42(26.3)$ & $16(31.4)$ & $108(84.4)$ & $79(95.2)$ & $<0.001$ \\
\hline GRACE score $\geq 89, \mathrm{n}(\%)$ & $65(40.6)$ & $24(47.1)$ & $109(85.2)$ & $70(84.3)$ & $<0.001$ \\
\hline SYNTAX score $\geq 23, \mathrm{n}(\%)$ & $5(3.1)$ & $2(3.9)$ & $31(24.2)$ & $27(32.5)$ & $<0.001$ \\
\hline MACEs, n (\%) & $13(8.1)$ & $7(13.7)$ & $30(23.4)$ & $26(31.3)$ & $<0.001$ \\
\hline Cardiac death, n (\%) & $2(1.3)$ & $1(2.0)$ & $6(4.7)$ & $7(8.4)$ & 0.036 \\
\hline Non-fatal MI, n (\%) & $3(1.9)$ & $3(5.9)$ & $8(6.3)$ & $6(7.2)$ & 0.116 \\
\hline TVR, n (\%) & $4(2.5)$ & $3(5.9)$ & $9(7.0)$ & $8(9.6)$ & 0.086 \\
\hline Heart failure, n (\%) & $2(1.3)$ & $0(0)$ & $5(3.9)$ & $4(4.8)$ & 0.182 \\
\hline Non-fatal stroke, n (\%) & $2(1.3)$ & $0(0)$ & $2(1.6)$ & $1(1.2)$ & 1.000 \\
\hline
\end{tabular}

Data are expressed as $\mathrm{n}(\%) . P$ value is from Chi-square test or Fisher exact test.

Abbreviations. CRP: C-reaction protein; BNP: B-type natriuretic peptide; MACEs: major adverse cardiovascular events; MI: myocardial Infarction; TVR: target vessel revascularization; MetS: metabolic syndrome.

(2) cystatin C level was independently associated with MetS; and (3) cystatin $C$ level was an independent predictor of MACEs during 12-month follow-up.

Renal impairment reflected by decreased GFR is known as an important cardiovascular risk factor [33]. Considering that direct measurement of GFR is cumbersome and not conductive to clinical application, renal function is mainly evaluated by estimated GFR (eGFR) based on the level of creatinine or cystatin $\mathrm{C}$ [3]. As circulating creatinine consists of GFR determinants and non-GFR determinants, circulating concentration of cystatin $\mathrm{C}$ has also been reported not to be entirely dependent on filtration rate, and its expression and secretion are regulated by several potential mechanisms $[10,34]$. Recent studies further indicated that non-GFR determinants of cystatin C participated in many physiological processes and played an important role in vascular biology [35]. Elevated circulating cystatin $\mathrm{C}$ level not only represents reduced GFR but also may reflect the compensation for increased elastolytic activity and the response to increased inflammatory factors and oxidative stress $[11,16]$. Hence, the 
TABLE 4: Summary of ROC curves.

\begin{tabular}{|c|c|c|c|c|c|c|c|}
\hline & AUC & $95 \% \mathrm{CI}$ & $P$ value & Cys $\mathrm{C}$ cutoff $(\mathrm{mg} / \mathrm{L})$ & Sensitivity & Specificity & Youden index \\
\hline $\mathrm{CRP}>5 \mu \mathrm{g} / \mathrm{mL}$ & 0.793 & $(0.749-0.837)$ & $<0.001$ & 0.85 & 0.782 & 0.719 & 0.501 \\
\hline $\mathrm{BNP}>100 \mathrm{pg} / \mathrm{mL}$ & 0.658 & $(0.605-0.712)$ & $<0.001$ & 1.02 & 0.464 & 0.811 & 0.275 \\
\hline Killip class $>1$ & 0.774 & $(0.727-0.822)$ & $<0.001$ & 0.93 & 0.722 & 0.742 & 0.465 \\
\hline Multivessel disease & 0.887 & $(0.858-0.919)$ & $<0.001$ & 0.91 & 0.751 & 0.887 & 0.638 \\
\hline SYNTAX score $\geq 23$ & 0.798 & $(0.741-0.854)$ & $<0.001$ & 0.99 & 0.754 & 0.748 & 0.502 \\
\hline GRACE score $\geq 89$ & 0.781 & $(0.737-0.826)$ & $<0.001$ & 0.90 & 0.672 & 0.786 & 0.457 \\
\hline MetS & 0.627 & $(0.569-0.685)$ & $<0.001$ & 1.01 & 0.440 & 0.757 & 0.197 \\
\hline MACEs & 0.723 & $(0.664-0.783)$ & $<0.001$ & 0.87 & 0.816 & 0.497 & 0.313 \\
\hline Cardiac death & 0.703 & $(0.595-0.811)$ & 0.006 & 0.89 & 0.875 & 0.485 & 0.360 \\
\hline Non-fatal MI & 0.676 & $(0.558-0.793)$ & 0.008 & 1.03 & 0.550 & 0.736 & 0.286 \\
\hline TVR & 0.699 & $(0.609-0.790)$ & 0.001 & 0.82 & 0.958 & 0.369 & 0.328 \\
\hline Heart failure & 0.708 & $(0.567-0.848)$ & 0.019 & 0.96 & 0.727 & 0.630 & 0.357 \\
\hline
\end{tabular}

Abbreviations. Cys C: cystatin C; CRP: C-reaction protein; BNP: B-type natriuretic peptide; MetS: metabolic syndrome; MACEs: major adverse cardiovascular events; MI: myocardial infarction; TVR: target vessel revascularization.

TABLE 5: Univariate and multivariate logistic regression analyses for metabolic syndrome.

\begin{tabular}{|c|c|c|c|c|c|c|}
\hline & \multicolumn{3}{|c|}{ Univariate } & \multicolumn{3}{|c|}{ Multivariate } \\
\hline & OR & $95 \% \mathrm{CI}$ & $P$ value & OR & $95 \% \mathrm{CI}$ & $P$ value \\
\hline Age & 0.999 & $(0.979-1.019)$ & 0.901 & & & \\
\hline Male & 1.516 & $(0.965-2.381)$ & 0.071 & 1.181 & $(0.571-2.442)$ & 0.654 \\
\hline BMI & 1.41 & $(1.291-1.541)$ & $<0.001$ & 1.378 & $(1.242-1.530)$ & $<0.001$ \\
\hline Smoking & 1.529 & $(1.013-2.310)$ & 0.043 & 0.932 & $(0.498-1.744)$ & 0.825 \\
\hline Hypertension & 2.317 & $(1.504-3.570)$ & $<0.001$ & 2.541 & $(1.438-4.489)$ & 0.001 \\
\hline Diabetes & 4.413 & $(2.834-6.872)$ & $<0.001$ & 3.208 & $(1.651-6.232)$ & 0.001 \\
\hline FBG & 1.278 & (1.151-1.419) & $<0.001$ & 1.07 & $(0.921-1.243)$ & 0.379 \\
\hline TG & 1.648 & $(1.365-1.991)$ & $<0.001$ & 1.277 & $(1.030-1.584)$ & 0.026 \\
\hline LDL-C & 1.132 & $(0.879-1.457)$ & 0.337 & & & \\
\hline HDL-C & 0.048 & $(0.018-0.133)$ & $<0.001$ & 0.068 & $(0.018-0.260)$ & $<0.001$ \\
\hline High cystatin C & 1.944 & $(1.280-2.952)$ & 0.002 & 2.299 & $(1.251-4.225)$ & 0.007 \\
\hline Uric acid & 1.005 & $(1.003-1.007)$ & $<0.001$ & 1.001 & $(0.997-1.004)$ & 0.659 \\
\hline eGFR-MDRD & 0.989 & $(0.980-0.999)$ & 0.035 & 0.993 & $(0.978-1.007)$ & 0.312 \\
\hline CRP & 1.012 & $(0.998-1.026)$ & 0.096 & 0.996 & $(0.979-1.014)$ & 0.682 \\
\hline D-dimer & 1.005 & $(0.866-1.166)$ & 0.948 & & & \\
\hline Fibrinogen & 0.993 & $(0.971-1.016)$ & 0.566 & & & \\
\hline
\end{tabular}

High cystatin C is defined as cystatin C concentration $>0.90 \mathrm{mg} / \mathrm{L}$.

Abbreviations. BMI: body mass index; FBG: fasting blood glucose; TG: triglyceride; LDL-C: low-density lipoprotein cholesterol; HDL-C: high-density lipoprotein cholesterol; eGFR-MDRD: estimated glomerular filtration rate based on MDRD equation; CRP: C-reaction protein.

TABLE 6: Association between Cystatin C and cardiovascular outcomes.

\begin{tabular}{|c|c|c|c|c|c|c|c|c|c|}
\hline \multirow[b]{2}{*}{ Outcome variables } & \multicolumn{3}{|c|}{ Unadjusted } & \multicolumn{3}{|c|}{ Adjusted model 1} & \multicolumn{3}{|c|}{ Adjusted model 2} \\
\hline & HR & $95 \% \mathrm{CI}$ & $P$ value & HR & $95 \% \mathrm{CI}$ & $P$ value & HR & $95 \% \mathrm{CI}$ & $P$ value \\
\hline MACEs & 2.876 & $(1.739-4.756)$ & $<0.001$ & 2.677 & $(1.566-4.576)$ & $<0.001$ & 2.609 & $(1.295-5.257)$ & 0.007 \\
\hline Cardiac death & 4.780 & $(1.362-16.778)$ & 0.015 & 4.147 & $(1.097-15.672)$ & 0.036 & 4.400 & $(0.845-22.896)$ & 0.078 \\
\hline Non-fatal MI & 2.036 & $(0.812-5.106)$ & 0.129 & 2.373 & $(0.887-6.346)$ & 0.085 & 4.041 & $(1.023-15.964)$ & 0.046 \\
\hline TVR & 2.649 & $(1.098-6.390)$ & 0.030 & 2.351 & $(0.912-6.062)$ & 0.077 & 1.563 & $(0.426-5.731)$ & 0.500 \\
\hline Heart failure & 4.955 & $(1.070-22.942)$ & 0.041 & 3.000 & $(0.589-15.293)$ & 0.186 & 2.958 & $(0.355-24.633)$ & 0.316 \\
\hline Non-fatal stroke & 1.677 & $(0.280-10.043)$ & 0.571 & 1.750 & $(0.281-10.894)$ & 0.548 & 1.787 & $(0.111-28.837)$ & 0.682 \\
\hline
\end{tabular}

High cystatin C is defined as cystatin C concentration $>0.90 \mathrm{mg} / \mathrm{L}$.

Univariate and multivariate Cox proportional regression analyses are applied.

Model 1 is adjusted for age, gender, BMI, smoking, hypertension, diabetes, LDL-C, and HDL-C.

Model 2 is adjusted for model 1, eGFR-MDRD, CRP, Killip class > 1, GRACE score, SYNTAX score, ACEI/ARB, beta-blocker, and PCI/CABG.

Abbreviations. MACEs: major adverse cardiovascular events; MI: myocardial infarction; TVR: target vessel revascularization. 


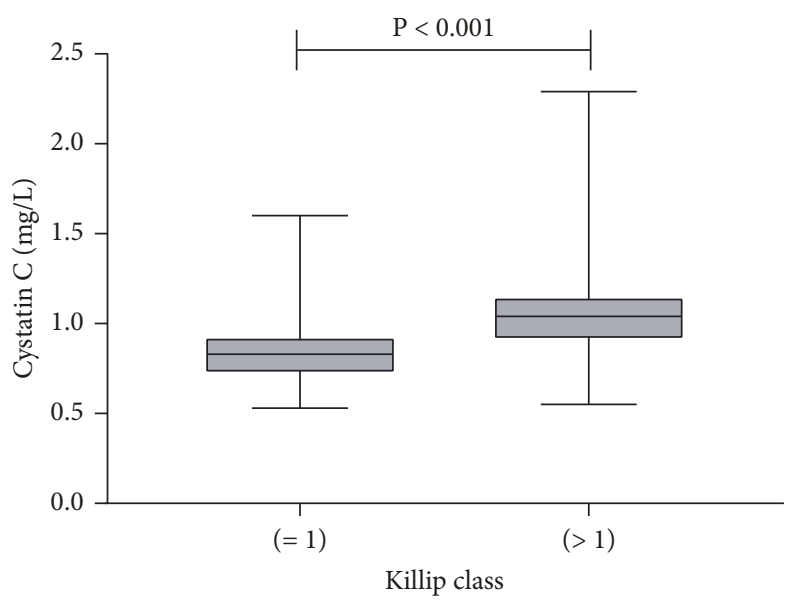

(a)

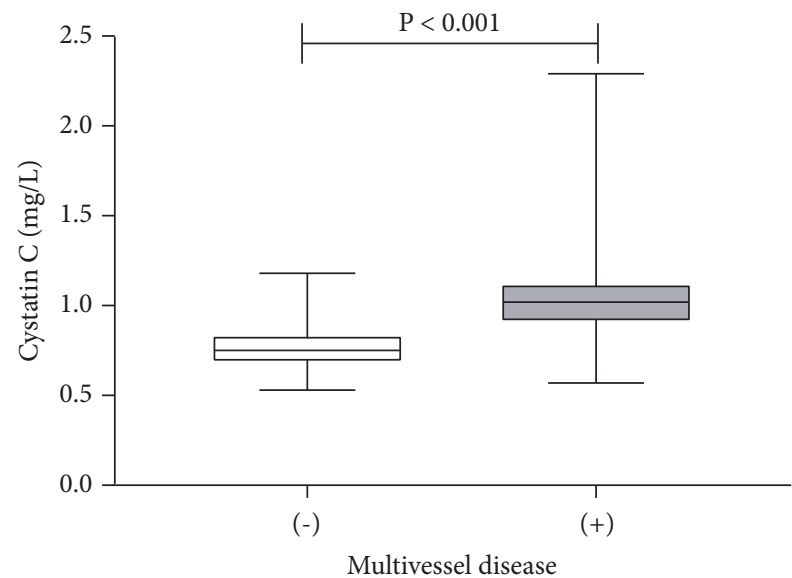

(c)

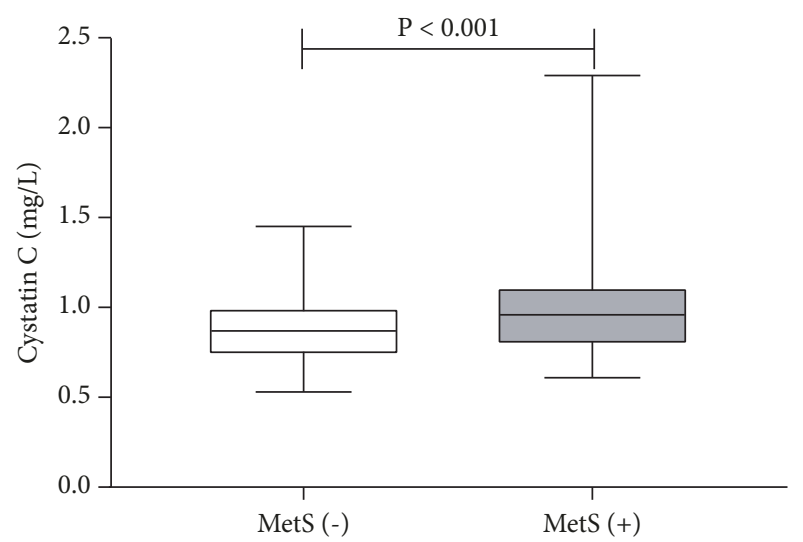

(e)

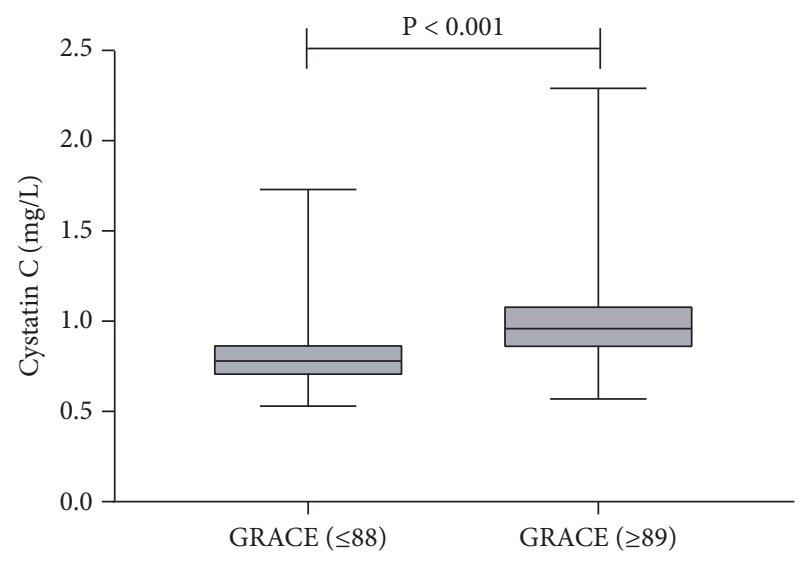

(b)

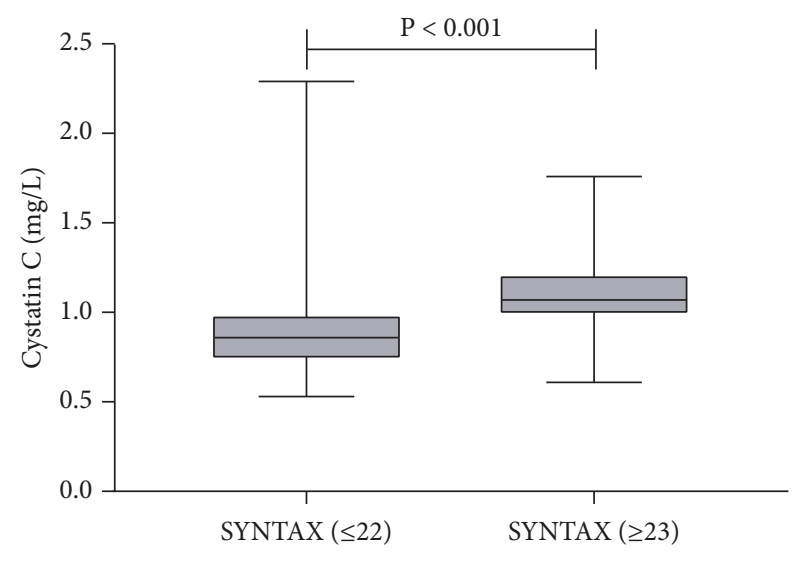

(d)

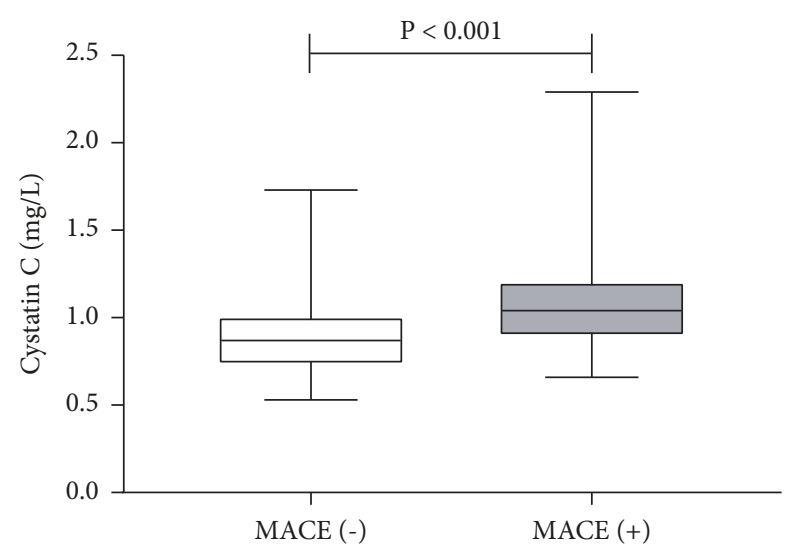

(f)

FIGURE 1: Comparisons of cystatin C levels in NSTE-ACS with or without Killip class > 1 (a), high GRACE score (b), multivessel disease (c), high SYNTAX score (d), metabolic syndrome (e), and MACE (f) by using the Mann-Whitney U test. MetS: metabolic syndrome; MACE: major adverse cardiovascular events.

prominent predictive effect of cystatin C on CVD should not simply interpreted by the filtration rates. However, until now the relationship between non-GFR determinants of cystatin $\mathrm{C}$ and cardiovascular risk factors had been controversial, and the potential mechanisms involved in cardiovascular outcomes were unclear [36].
Previous evidence revealed the significant association between cystatin $\mathrm{C}$ and metabolic risk factors, such as dyslipidemia, diabetes, and hypertension [19, 20, 37]. Our findings provided further insight into the potential link between cystatin C and MetS in NSTE-ACS. First, our results showed the correlation of cystatin $\mathrm{C}$ with metabolic parameters and 

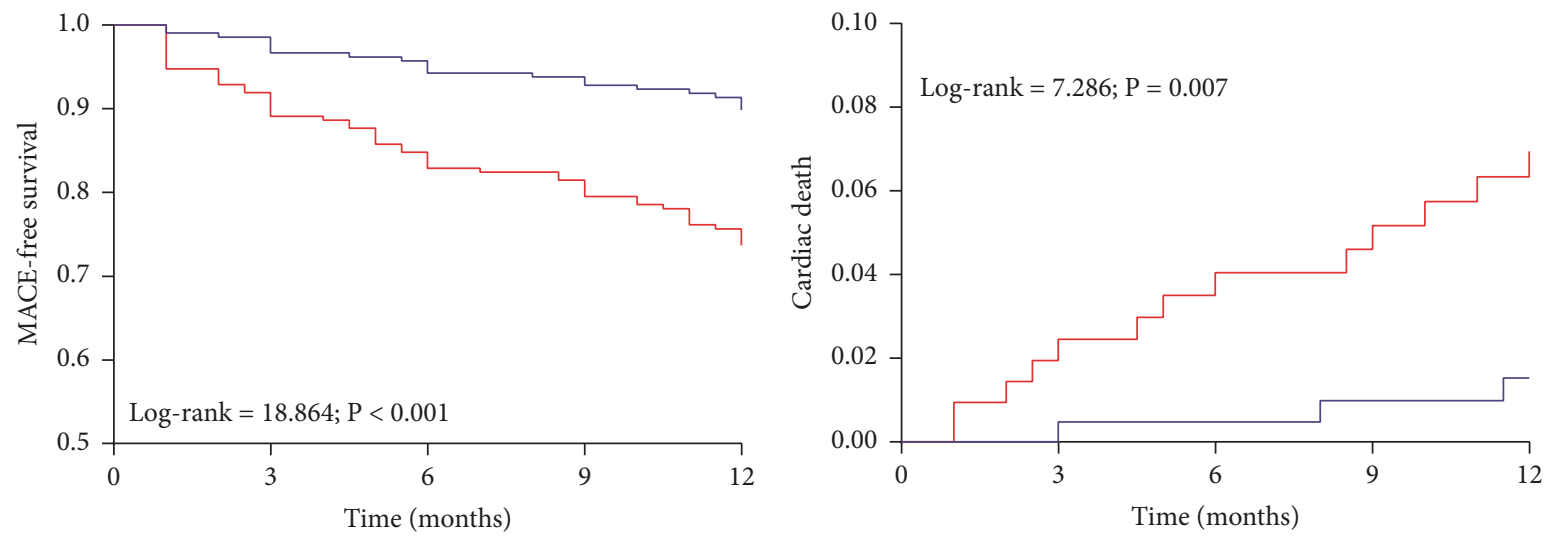

Cystatin C

Cystatin C

- Low

- Low

— High

(a)
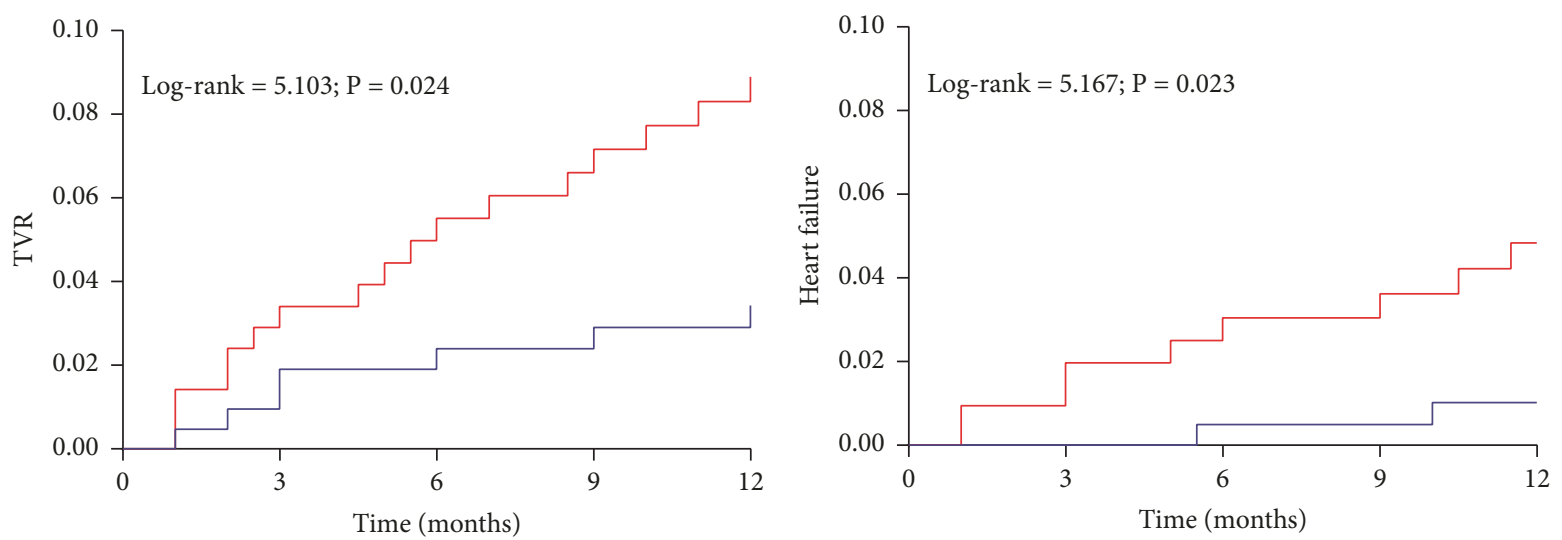

Cystatin C

Cystatin C

- Low

— Low

— High

(c)

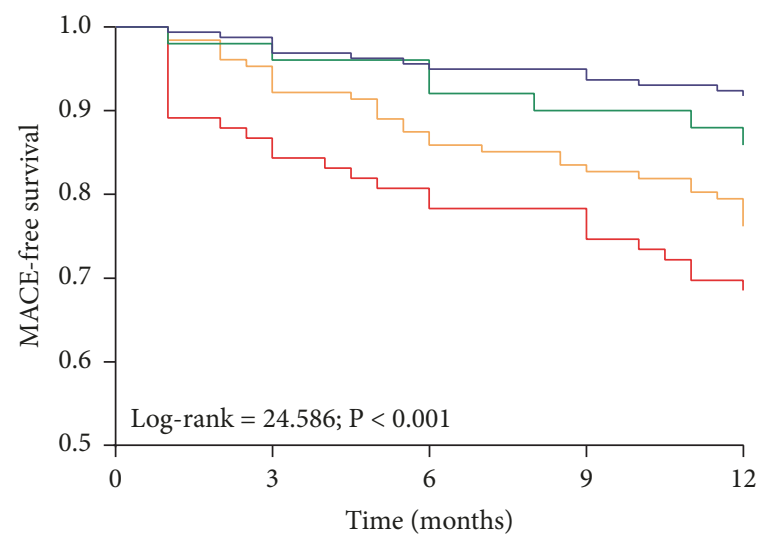

(d)

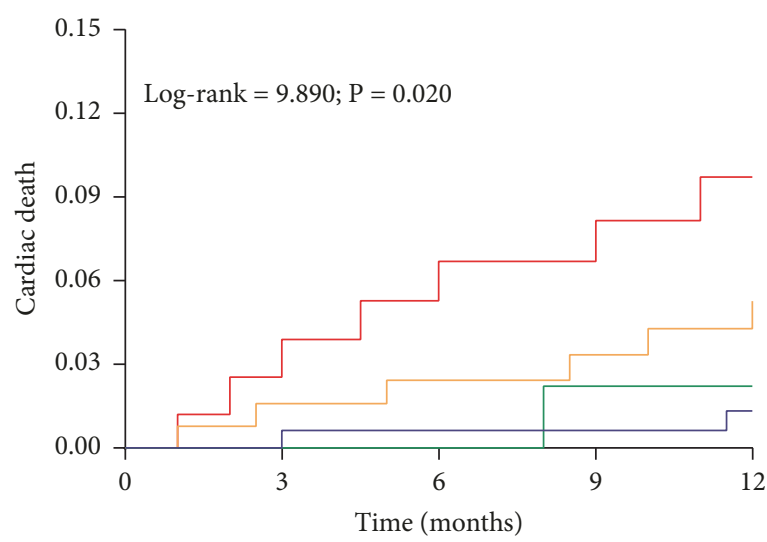

Cystatin C/MetS

$\begin{array}{ll}\text { Low/MetS }(-) & \text { High/MetS }(-) \\ - \text { Low/MetS } & (+) \quad \text { High/MetS }(+)\end{array}$

Cystatin C/MetS

$\begin{array}{ll}- \text { Low/MetS (-) } & \text { High/MetS (-) } \\ - \text { Low/MetS }(+) & \text { High/MetS }(+)\end{array}$

(e)

(f)

FIGURE 2: Kaplan-Meier curves for survival analysis of MACE-free $(a, e)$; cumulative hazard curves for cardiac death $(b, f)$, TVR $(c)$, and heart failure (d). Significant differences between groups were assessed by the log-rank test. MACE: major adverse cardiovascular events; TVR: target vessel revascularization. 
inflammation markers rather than creatinine. Second, we observed that patients with higher cystatin C levels had worsened conditions of MetS compared to those with low cystatin C levels. Consistent with our results, Surenda et al. [19] noted that cystatin C level increased with increasing number of metabolic abnormalities in the Asian population with normal glucose tolerance; and Servais et al. [38] reported that cystatin $\mathrm{C}$ was significantly higher in patients with MetS independent of creatinine level. However, these studies were mainly based on general population, as until now no studies have been focused solely on patients with ACS. Hence, our results were complementary to previous observations. Third, the ROC curve analysis indicated that cystatin C might serve as a diagnostic indicator for MetS. The results reconfirmed the correlation with MetS and suggested that non-GFR determinants of cystatin $\mathrm{C}$ might participate in the process of metabolic disorder. In this context, elevated cystatin $\mathrm{C}$ level may contribute to identify the patients with MetS for risk stratification.

In previous studies, Magnusson et al. [18] reported that cystatin C might contribute to development of MetS by affecting metabolic parameters in general population, and Vigil et al. [20] showed that circulating cystatin $C$ included several non-GFR determinants by multiple linear regression analysis in a hypertension population with a larger proportion of MetS. In the present study, we found that cystatin C remained to be an independent predictor of MetS even after adjustment for eGFR and other risk factors in multivariate analysis. The independent effect of cystatin C on MetS might be attributed to metabolic factors related with cystatin C. A few studies showed that high cystatin $\mathrm{C}$ level was associated with central adiposity characterized by visceral fat accumulation [39-41]. Further evidence suggested that cathepsin/cystatin system regulated the differentiation of preadipocyte and adipocyte to promote fat accumulation $[42,43]$. Recent studies also indicated that the relationship between cystatin $\mathrm{C}$ and diabetes was dependent of central adiposity, and cystatin $\mathrm{C}$ was significantly associated with IR independent of filtration rate $[44,45]$. Visceral fat accumulation is known to be strongly associated with insulin resistance (IR) that contributes to the pathogenesis of MetS [21, 46]. Thus, high cystatin C level may reflect visceral fat accumulation and increased insulin resistance. Furthermore, human tissue biopsy data revealed that both cathepsin and cystatin $\mathrm{C}$ were highly expressed in adipose tissue inflammation, which is closely related to IR and MetS [39]. Due to the inhibition of cathepsin by cystatin $\mathrm{C}$, these findings suggested that cystatin $\mathrm{C}$ might contribute to controlling adipose tissue homeostasis and to inhibiting cathepsin-induced inflammation by countering the activation of cathepsin [41]. Therefore, elevated non-GFR determinants of cystatin $\mathrm{C}$ may represent the response to adipose tissue remodeling and the progression of insulin resistance. The relationship of cystatin $\mathrm{C}$ with MetS may be further associated with IR dependent on non-GFR determinants of cystatin C. Moreover, IR reflected by cystatin $\mathrm{C}$ could also independently elucidate the association of cystatin $\mathrm{C}$ with other cardiovascular risk factors, such as SYNTAX score and GRACE score, in NSTE-ACS with preserved renal function.
In the current study, we found that cystatin $\mathrm{C}$ was a strong independent predictor of MACEs in NSTE-ACS, even after adjustment for CRP, MetS, eGFR, and SYNTAX scores. The results indicated that non-GFR determinants of cystatin $\mathrm{C}$ were associated with cardiovascular outcomes, which was supported by previous studies that directly measured GFR thus avoiding errors of eGFR [47, 48]. Similarly, the Ludwigshafen Risk and Cardiovascular Health (LURIC) study also demonstrated that cystatin $\mathrm{C}$ was predictive for all-cause and cardiovascular mortality independent of renal function [49]. Hence, the predictive role of cystatin C could not be simply ascribed to renal impairment but further extended to functions in vascular remodeling and plaque instability. Therefore, the underlying mechanisms by which non-GFR determinants of cystatin $\mathrm{C}$ affect cardiovascular outcomes may be as follows: first, cystatin $\mathrm{C}$ may induce inflammation and promote the progression of atherosclerosis [50]. Second, cystatin $\mathrm{C}$ may directly mediate the degradation of vascular matrix, remodel coronary artery wall, and reconstruct plaque [51]. Third, IR reflected by cystatin $\mathrm{C}$ may contribute to plaque instability [52]. The rupture of unstable plaque was the leading cause of acute myocardial infarction, increased plaque burden determined ischemic-driven revascularization, and finally continuous myocardial ischemia and ventricular remodeling greatly increased risk of cardiovascular death $[23,53]$. In addition, IR reflected by cystatin $\mathrm{C}$ may also promote sympathetic activity, activate the renin-angiotensinaldosterone system, and ultimately increase the incidence of MACEs [54, 55].

Our study had several limitations. Firstly, this was a single center and observational study with potential selection bias. Second, our sample size was relatively small, and follow-up duration was short. Third, laboratory parameters were only measured once at admission with potential bias due to measurement error. Fourth, our study failed to rely on direct GFR measurement to assess the association of GFR with cardiovascular risk factors and outcomes that could not completely exclude the compounded effect of GFR on the predictive role of cystatin C [11]. Fifth, IR and MetS are considered to be associated with glomerular hyperfiltration in early renal impairment and may increase cystatin $\mathrm{C}$ level due to IR underestimated hyperfiltration [56]. Finally, since our study population is of Chinese origin, further population-based studies are required before extrapolating the findings of this study to make a general conclusion.

\section{Conclusion}

Our study indicated that non-GFR determinants of cystatin $\mathrm{C}$ might be an independent predictor of MetS and cardiovascular outcomes in NSTE-ACS. Cystatin C links renal impairment, insulin resistance, vascular remodeling, and cardiovascular risk as a cardiorenal metabolic marker. The detection of cystatin C may be helpful for management of NSTE-ACS to decrease cardiovascular events. Given the limitations of current study, further multicenter, large-scale, long follow-up period studies are required to assess the implication of these results. 


\section{Data Availability}

The data used to support the findings of this study are available from the corresponding author upon request.

\section{Conflicts of Interest}

The authors have no conflicts of interest to declare.

\section{Acknowledgments}

The authors acknowledge all the participants for their support. This study was supported by grants from the National Natural Science Foundation of China (nos. 81370213 and 81670428).

\section{References}

[1] O. F. Laterza, C. P. Price, and M. G. Scott, "Cystatin C: an improved estimator of glomerular filtration rate?" Clinical Chemistry, vol. 48, no. 5, pp. 699-707, 2002.

[2] L. A. Stevens, J. Coresh, T. Greene, and A. S. Levey, "Assessing kidney function-measured and estimated glomerular filtration rate," The New England Journal of Medicine, vol. 354, no. 23, pp. 2473-2483, 2006.

[3] L. A. Inker, C. H. Schmid, H. Tighiouart et al., "Estimating glomerular filtration rate from serum creatinine and cystatin C," The New England Journal of Medicine, vol. 367, no. 1, pp. 20-29, 2012.

[4] M. E. Grams, S. P. Juraschek, E. Selvin et al., "Trends in the prevalence of reduced GFR in the United States: a comparison of creatinine- and cystatin c-based estimates," American Journal of Kidney Diseases, vol. 62, no. 2, pp. 253-260, 2013.

[5] T. Jernberg, B. Lindahl, S. James, A. Larsson, L.-O. Hansson, and L. Wallentin, "Cystatin C: a novel predictor of outcome in suspected or confirmed non-ST-elevation acute coronary syndrome," Circulation, vol. 110, no. 16, pp. 2342-2348, 2004.

[6] A. Åkerblom, L. Wallentin, A. Larsson et al., "Cystatin C- and creatinine-based estimates of renal function and their value for risk prediction in patients with acute coronary syndrome: Results from the PLATelet inhibition and patient outcomes (PLATO) study," Clinical Chemistry, vol. 59, no. 9, pp.1369-1375, 2013.

[7] E. L. Schiffrin, M. L. Lipman, and J. F. E. Mann, "Chronic kidney disease: effects on the cardiovascular system," Circulation, vol. 116, no. 1, pp. 85-97, 2007.

[8] S. Correa, D. A. Morrow, E. Braunwald et al., "Cystatin C for risk stratification in patients after an acute coronary syndrome," Journal of the American Heart Association, vol. 7, no. 20, 2018.

[9] F. Latta and C. de Filippi, "Role for cystatin C-based risk stratification for patients after acute coronary syndrome in the era of high sensitivity cardiac troponin assays," Journal of the American Heart Association, vol. 7, no. 20, 2018.

[10] E. L. Knight, J. C. Verhave, D. Spiegelman et al., "Factors influencing serum cystatin $\mathrm{C}$ levels other than renal function and the impact on renal function measurement," Kidney International, vol. 65, no. 4, pp. 1416-1421, 2004.

[11] E. R. Smith, "Cystatin C - More than a filtration marker?" Atherosclerosis, vol. 230, no. 1, pp. 73-75, 2013.

[12] W. Koenig, D. Twardella, H. Brenner, and D. Rothenbacher, "Plasma concentrations of cystatin $\mathrm{C}$ in patients with coronary heart disease and risk for secondary cardiovascular events: more than simply a marker of glomerular filtration rate," Clinical Chemistry, vol. 51, no. 2, pp. 321-327, 2005.

[13] G. Luc, J.-M. Bard, C. Lesueur et al., "Plasma cystatin-C and development of coronary heart disease: The PRIME Study," Atherosclerosis, vol. 185, no. 2, pp. 375-380, 2006.

[14] N. Taglieri, D. J. Fernandez-Berges, W. Koenig et al., "Plasma cystatin $\mathrm{C}$ for prediction of 1-year cardiac events in Mediterranean patients with non-ST elevation acute coronary syndrome," Atherosclerosis, vol. 209, no. 1, pp. 300-305, 2010.

[15] T. Okura, M. Jotoku, J. Irita et al., "Association between cystatin $\mathrm{C}$ and inflammation in patients with essential hypertension," Clinical and Experimental Nephrology, vol. 14, no. 6, pp. 584588, 2010.

[16] J. V. Salgado, F. L. Souza, and B. J. Salgado, "How to understand the association between cystatin $\mathrm{C}$ levels and cardiovascular disease: Imbalance, counterbalance, or consequence?" Journal of Cardiology, vol. 62, no. 6, pp. 331-335, 2013.

[17] M. Magnusson, J. Molvin, G. Engström et al., "Cystatin C and risk of diabetes and the metabolic syndrome - biomarker and genotype association analyses," PLOS ONE, vol. 11, no. 5, p. e0155735, 2016.

[18] M. Magnusson, B. Hedblad, G. Engström, M. Persson, P. Nilsson, and O. Melander, "High levels of cystatin C predict the metabolic syndrome: The prospective Malmö Diet and Cancer Study," Journal of Internal Medicine, vol. 274, no. 2, pp. 192-199, 2013.

[19] J. Surendar, K. Indulekha, V. Aravindhan, A. Ganesan, and V. Mohan, "Association of cystatin-C with metabolic syndrome in normal glucose-tolerant subjects (CURES-97)," Diabetes Technology \& Therapeutics, vol. 12, no. 11, pp. 907-912, 2010.

[20] L. Vigil, M. Lopez, E. Condés et al., "Cystatin C is associated with the metabolic syndrome and other cardiovascular risk factors in a hypertensive population," Journal of the American Society of Hypertension, vol. 3, no. 3, pp. 201-209, 2009.

[21] R. H. Eckel, S. M. Grundy, and P. Z. Zimmet, "The metabolic syndrome," The Lancet, vol. 365, no. 9468, pp. 1415-1428, 2005.

[22] Y. Arbel, O. Havakuk, A. Halkin et al., "Relation of metabolic syndrome with long-term mortality in acute and stable coronary disease," American Journal of Cardiology, vol. 115, no. 3, pp. 283-287, 2015.

[23] A. Synetos, A. Papanikolaou, K. Toutouzas et al., "Metabolic syndrome predicts plaque rupture in patients with acute myocardial infarction. An optical coherence study," International Journal of Cardiology, vol. 209, pp. 139-141, 2016.

[24] M. G. Shlipak, M. J. Sarnak, R. Katz et al., "Cystatin C and the risk of death and cardiovascular events among elderly persons," The New England Journal of Medicine, vol. 352, no. 20, pp. 20492060, 2005.

[25] M. Roffi, C. Patrono, and J.-P. Collet, "2015 ESC guidelines for the management of acute coronary syndromes in patients presenting without persistent ST-segment elevation," European Heart Journal, 2015.

[26] K. A. A. Fox, O. H. Dabbous, R. J. Goldberg et al., "Prediction of risk of death and myocardial infarction in the six months after presentation with acute coronary syndrome: Prospective multinational observational study (GRACE)," British Medical Journal, vol. 333, no. 7578, pp. 1091-1094, 2006.

[27] B. Vogel, S. R. Mehta, and R. Mehran, "Reperfusion strategies in acute myocardial infarction and multivessel disease," Nature Reviews Cardiology, vol. 14, no. 11, pp. 665-678, 2017. 
[28] T. Palmerini, P. Genereux, A. Caixeta et al., "Prognostic value of the SYNTAX score in patients with acute coronary syndromes undergoing percutaneous coronary intervention," Journal of the American College of Cardiology, vol. 57, no. 24, pp. 2389-2397, 2011.

[29] S. M. Grundy, J. I. Cleeman, S. R. Daniels et al., "Diagnosis and management of the metabolic syndrome: an American Heart Association/National Heart, Lung, and Blood Institute scientific statement," Circulation, vol. 112, no. 17, pp. 2735-2752, 2005.

[30] A. S. Levey, L. A. Stevens, C. H. Schmid et al., "A new equation to estimate glomerular filtration rate," Annals of Internal Medicine, vol. 150, no. 9, pp. 604-612, 2009.

[31] P. M. Ridker, B. M. Everett, T. Thuren et al., "Antiinflammatory therapy with canakinumab for atherosclerotic disease," The New England Journal of Medicine, vol. 377, no. 12, pp. 1119-1131, 2017.

[32] I. S. Anand, B. Claggett, J. Liu et al., "Interaction between spironolactone and natriuretic peptides in patients with heart failure and preserved ejection fraction: from the TOPCAT trial," JACC: Heart Failure, vol. 5, no. 4, pp. 241-252, 2017.

[33] N. Taglieri, W. Koenig, and J. C. Kaski, "Cystatin C and cardiovascular risk," Clinical Chemistry, vol. 55, no. 11, pp. 19321943, 2009.

[34] C. W. Tsai, M. E. Grams, L. A. Inker, J. Coresh, and E. Selvin, "Cystatin C- and creatinine-based estimated glomerular filtration rate, vascular disease, and mortality in persons with diabetes in the U.S.," Diabetes Care, vol. 37, no. 4, pp. 1002-1008, 2014.

[35] Y. Xu, Y. Ding, X. Li, and X. Wu, "Cystatin C is a diseaseassociated protein subject to multiple regulation," Immunology \& Cell Biology, vol. 93, no. 5, pp. 442-451, 2015.

[36] S. W. van der Laan, T. Fall, A. Soumare et al., "Cystatin C and cardiovascular disease: a mendelian randomization study," Journal of the American College of Cardiology, vol. 68, no. 9, pp. 934-945, 2016.

[37] R. P. Donahue, S. Stranges, K. Rejman, L. B. Rafalson, J. Dmochowski, and M. Trevisan, "Elevated cystatin C concentration and progression to pre-diabetes: The Western New York Study," Diabetes Care, vol. 30, no. 7, pp. 1724-1729, 2007.

[38] A. Servais, P. Giral, M. Bernard, E. Bruckert, G. Deray, and C. Isnard Bagnis, "Is serum cystatin-C a reliable marker for metabolic syndrome?" American Journal of Medicine, vol. 121, no. 5, pp. 426-432, 2008.

[39] N. Naour, S. Fellahi, J.-F. Renucci et al., "Potential contribution of adipose tissue to elevated serum cystatin C in human obesity," Obesity, vol. 17, no. 12, pp. 2121-2126, 2009.

[40] T. Murai, N. Takebe, K. Nagasawa et al., "Association of epicardial adipose tissue with serum level of cystatin C in type 2 diabetes," PLoS ONE, vol. 12, no. 9, p. e0184723, 2017.

[41] A. P. J. de Vries and T. J. Rabelink, "A possible role of cystatin $\mathrm{C}$ in adipose tissue homeostasis may impact kidney function estimation in metabolic syndrome," Nephrology Dialysis Transplantation, vol. 28, no. 7, pp. 1628-1630, 2013.

[42] S. Taleb, R. Cancello, K. Clément, and D. Lacasa, "Cathepsin S promotes human preadipocyte differentiation: Possible involvement of fibronectin degradation," Endocrinology, vol. 147, no. 10, pp. 4950-4959, 2006.

[43] N. Naour, C. Rouault, S. Fellahi et al., "Cathepsins in human obesity: Changes in energy balance predominantly affect cathepsin S in adipose tissue and in circulation," The Journal of Clinical Endocrinology \& Metabolism, vol. 95, no. 4, pp. 18611868, 2010.
[44] A. T. Reutens, F. Bonnet, O. Lantieri, R. Roussel, and B. Balkau, "The association between cystatin $\mathrm{C}$ and incident type 2 diabetes is related to central adiposity," Nephrology Dialysis Transplantation, vol. 28, no. 7, pp. 1820-1829, 2013.

[45] S.-H. Lee, S.-A. Park, S.-H. Ko et al., "Insulin resistance and inflammation may have an additional role in the link between cystatin $\mathrm{C}$ and cardiovascular disease in type 2 diabetes mellitus patients," Metabolism - Clinical and Experimental, vol. 59, no. 2, pp. 241-246, 2010.

[46] J.-P. Després and I. Lemieux, "Abdominal obesity and metabolic syndrome," Nature, vol. 444, no. 7121, pp. 881-887, 2006.

[47] U. D. Mathisen, T. Melsom, O. C. Ingebretsen et al., "Estimated GFR associates with cardiovascular risk factors independently of measured GFR," Journal of the American Society of Nephrology, vol. 22, no. 5, pp. 927-937, 2011.

[48] N. Tangri, L. A. Inker, H. Tighiouart et al., "Filtration markers may have prognostic value independent of glomerular filtration rate," Journal of the American Society of Nephrology, vol. 23, no. 2, pp. 351-359, 2012.

[49] R. P. Woitas, M. E. Kleber, A. Meinitzer et al., "Cystatin $\mathrm{C}$ is independently associated with total and cardiovascular mortality in individuals undergoing coronary angiography. the ludwigshafen risk and cardiovascular health (LURIC) study," Atherosclerosis, vol. 229, no. 2, pp. 541-548, 2013.

[50] X. Qing, W. Furong, L. Yunxia, Z. Jian, W. Xuping, and G. Ling, "Cystatin $\mathrm{C}$ and asymptomatic coronary artery disease in patients with metabolic syndrome and normal glomerular filtration rate," Cardiovascular Diabetology, vol. 11, p. 108, 2012.

[51] G.-N. Wang, K. Sun, D.-L. Hu, H.-H. Wu, X.-Z. Wang, and J.S. Zhang, "Serum cystatin C levels are associated with coronary artery disease and its severity," Clinical Biochemistry, vol. 47, no. 16-17, pp. 176-181, 2014.

[52] M. Laakso and J. Kuusisto, "Insulin resistance and hyperglycaemia in cardiovascular disease development," Nature Reviews Endocrinology, vol. 10, no. 5, pp. 293-302, 2014.

[53] S. P. Marso, N. Mercado, A. Maehara et al., "Plaque composition and clinical outcomes in acute coronary syndrome patients with metabolic syndrome or diabetes," JACC: Cardiovascular Imaging, vol. 5, no. 3, pp. S42-S52, 2012.

[54] V. Ormazabal, S. Nair, O. Elfeky, C. Aguayo, C. Salomon, and F. A. Zuñiga, "Association between insulin resistance and the development of cardiovascular disease," Cardiovascular Diabetology, vol. 17, no. 1, p. 122, 2018.

[55] Q. Mao, D. Zhou, Y. Li, Y. Wang, S. Xu, and X. Zhao, "The triglyceride-glucose index predicts coronary artery disease severity and cardiovascular outcomes in patients with non-stsegment elevation acute coronary syndrome," Disease Markers, vol. 2019, Article ID 6891537, 11 pages, 2019.

[56] S.-H. S. Huang, A. P. Sharma, A. Yasin, R. M. Lindsay, W. F. Clark, and G. Filler, "Hyperfiltration affects accuracy of creatinine eGFR measurement," Clinical Journal of the American Society of Nephrology, vol. 6, no. 2, pp. 274-280, 2011. 


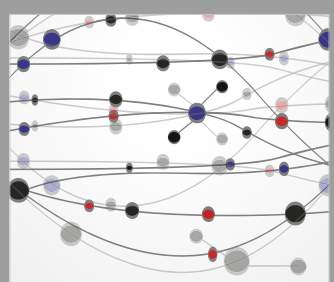

The Scientific World Journal
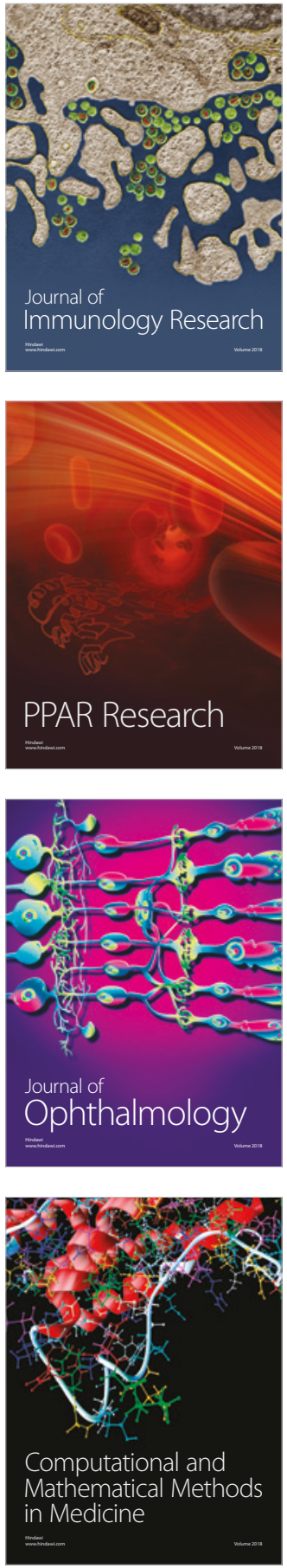

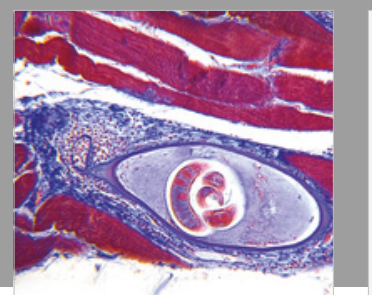

Gastroenterology Research and Practice

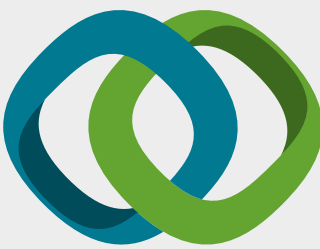

\section{Hindawi}

Submit your manuscripts at

www.hindawi.com
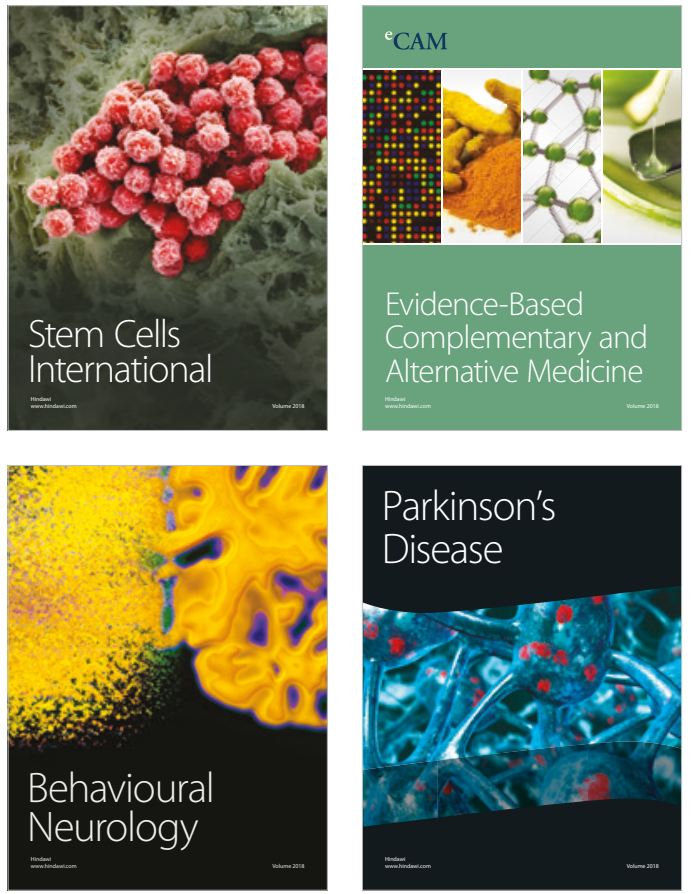

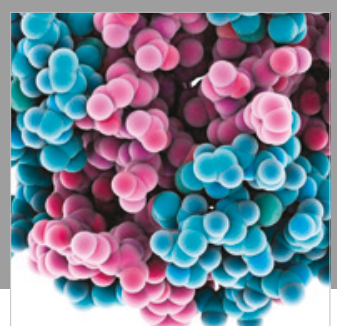

ournal of

Diabetes Research

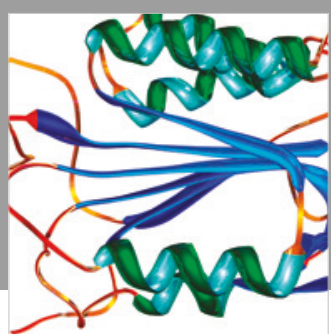

Disease Markers
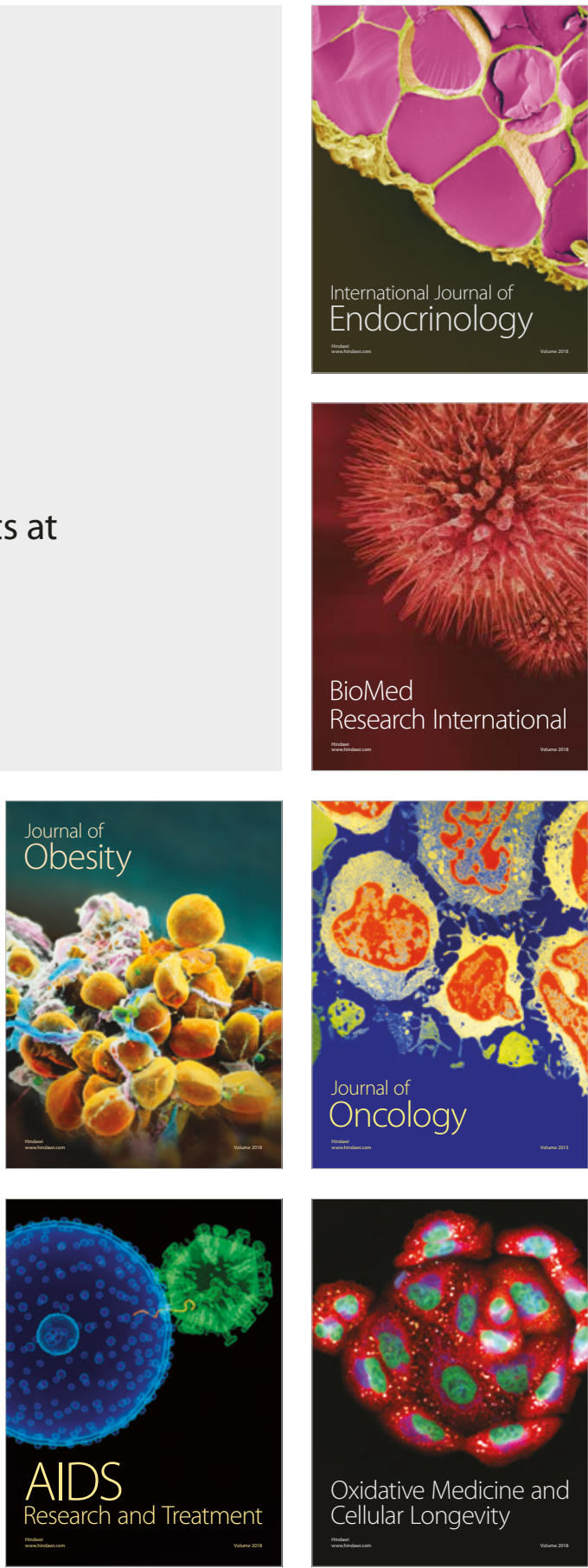